\title{
O PRESTÍGIO NA CAPA: A CONSTRUÇÃO JORNALÍSTICA DA FIGURA DO EDITOR DE LIVROS NO SUPLEMENTO SABÁTICO $[2010-2013]^{1}$
}

\author{
PRESTIGE ON THE COVER: THE

\section{JOURNALISTIC CONSTRUCTION OF THE BOOK EDITOR PERSONA IN THE SABÁTICO SUPPLEMENT [2010-2013]}

Edição v.35 número 2 / 2016

Contracampo e-ISSN 2238-2577

Niterói (RJ), v. 35, n. 2

ago/2016-nov/2016

A Revista Contracampo é uma revista eletrônica do Programa de Pós-Graduação em Comunicação da Universidade Federal Fluminense e tem como objetivo contribuir para a reflexão crítica em torno do campo midiático, atuando como espaço de circulação da pesquisa e do pensamento acadêmico.

\section{MARIANA SCALABRIN MÜLLER}

Mestre em Comunicação e Informação pelo Programa de Pós-Graduação em Comunicação e Informação (PPGCOM/UFRGS). Jornalista, editora-chefe do programa Estação Cultura da TVE-RS. Brasil.

marianasmuller@gmail.com

\section{CIDA GOLIN}

Doutora em Letras, professora do curso de Jornalismo e do curso de Museologia da FABICO-UFRGS e professora do PPGCOM-UFRGS na linha de Jornalismo e Produção Editorial. Pesquisadora do CNPq. Brasil.

cidago@terra.com.br

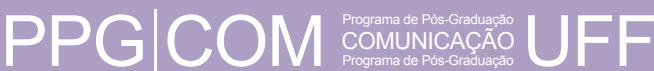

AO CITAR ESTE ARTIGO, UTILIZE A SEGUINTE REFERÊNCIA:

MÜLLER, Mariana S.; COSTA, Cassilda G. O prestígio na capa: a construção jornalística da figura do editor de livros no Suplemento Sabático (2010-2013). Contracampo, Niterói, v. 35, n. 02, pp. 116-136, ago./nov., 2016.

Enviado em 11 de novembro de 2015 / Aceito em: 10 de março de 2016

DOI: http://dx.doi.org/10.20505/contracampo.v35i2.938 


\section{Resumo}

Este artigo busca identificar os índices de prestígio acionados pelo suplemento Sabático (2010-2013) na construção jornalística da figura do editor de livros feita a partir da capa, espaço emblemático de consagração. Após mapeamento e análise de todas as 160 capas do extinto suplemento do jornal 0 Estado de S. Paulo, delimitamos nosso corpus a seis edições que tiveram na página principal um editor de livros. O aporte qualitativo da Análise de Conteúdo ( $\mathrm{AC}$ ) e o tensionamento com o referencial teórico apontaram para três categorias regulares e sistemáticas que respondem, no coletivo, à construção prestigiosa desses editores: Formação, Rede de Relações e Catálogo. A figura positiva dos editores, construída pela narrativa jornalística do Sabático, personaliza o sucesso das empresas aos elementos de distinção atribuídos a cada um desses profissionais.

\section{Palavras-chave}

suplemento cultural; Sabático; editor de livros.

\section{Abstract}

This paper aims to identify prestige indexes used by the cultural supplement Sabático (2010-2013) on its covers - an emblematic space of recognition - in the journalistic construction of book editors' image. After we gathered all Sabático's issues published by $\mathrm{O}$ Estado de S. Paulo (160 in total), we reduced our corpus to six issues that have book editors on their covers. The basis of the qualitative Content Analysis (CA) and the tension with the related theory points to three analytic categories, which are collectively related to the representation of these editors: Education, Networking, and Catalog. The positive image of editors created by Sabático's journalistic narrative personalizes the success of the companies when it relates these people to the distinction elements attributed to each of them.

\section{Keywords}

cultural supplement; Sabático; book editor. 


\section{Introdução}

O suplemento Sabático foi lançado pelo jornal O Estado de S. Paulo em março de 2010, a partir de uma proposta de recriar o encarte Cultura, publicado aos domingos. A iniciativa se transformou, conforme Costa (2012), em um novo caderno voltado especificamente para os livros, publicado aos sábados. A publicação foi apresentada editorialmente como um resgate do tradicional Suplemento Literário de O Estado de S. Paulo (1956-1974), em um momento em que os jornais impressos de diferentes países passavam por transformações tecnológicas e de mercado - muitas delas acarretando o fim de suplementos dedicados à cultura. Pouco mais de três anos depois, em abril de 2013, o Sabático deixou de circular, em outra reformulação editorial a qual o Estadão se submeteu.

O presente artigo, fruto de uma dissertação de mestrado, sintetiza parte dos resultados da análise de seis entrevistas com editores de livros realizadas pelo suplemento. Este corpus de pesquisa foi definido a partir de uma indexação panorâmica - focada no conteúdo das capas - das 160 edições publicadas ao longo de três anos de Sabático. Com aporte da Análise de Conteúdo, a panorâmica quantitativa apontou que a maior parte das capas (74\%) centrou-se em indivíduos, apresentados com uma foto ou caricatura na principal chamada da edição, evidenciando o uso recorrente da personalização enquanto recurso jornalístico. Entre as capas dedicadas a único um sujeito (108), percebemos o destaque conferido aos criadores: são 93 escritores, $86 \%$ do total. Apesar da presença dos editores ser numericamente inferior à dos escritores, entendemos que os editores ganharam expressão nas páginas do caderno, uma vez que ocuparam o espaço de maior hierarquia de um suplemento cultural - formato que já tem a distinção como uma de suas características. Além disso, o caderno sempre voltou-se ao mercado editorial, não necessariamente à literatura e, desse nicho, escolheu somente seis protagonistas para representar um segmento profissional amplo e muitas vezes marcado pelo anonimato no exercício de suas funções.

Desse modo, em ordem de publicação, os editores entrevistados são: Luiz Schwarcz, da Companhia das Letras; Jacó Guinsburg, da Perspectiva; Sergio Machado, da Record; Roberto Feith, da Objetiva; Alexandre e Evandro Martins Fontes, responsáveis, respectivamente, pelas editoras WMF - Martins Fontes e Martins Fontes - Selo Martins; Charles Cosac, da Cosac Naify. ${ }^{1}$ Nosso objetivo, portanto, é compreender a partir de quais indicadores de prestígio

1 Cinco entrevistas foram publicadas no formato pergunta e resposta, o pingue-pongue, acompanhadas de um texto curto de apresentação feito por jornalistas. Uma delas, com Jacó Guinsburg, foi publicada em texto assinado pelo jornalista Antônio Gonçalves Filho no estilo perfil. 
o suplemento Sabático constrói a figura do editor de livros.

\section{A construção jornalística dos editores de livros no suplemento perito}

Baseado em um contrato que tem valor fiduciário, o jornalismo é capaz de legitimar e deslegitimar, conferir visibilidade ou silenciar, formando supostos consensos sobre a cultura de uma época (Hall, 1999). Entendemos, conforme Miguel (1999), que a convicção que leitores e espectadores depositam nas notícias e nas reportagens faz com que o jornalismo também possa ser compreendido como um sistema perito. Ao fazer uso de outros sistemas de excelência, funciona ainda como um metassistema perito. Nesse processo, confere visibilidade e, ao mesmo tempo, coloca em dúvida a reputação daqueles que são preteridos.

De forma específica, os suplementos culturais são um espaço de prestígio do jornal, capaz de transferir capital simbólico para agentes e produtos, atuando como um mediador - que indica o que há de relevante - para o público. O fato de serem publicados semanalmente os distancia da lógica diária das notícias e permite a publicação de outros formatos, como ensaios e artigos (Golin et al., 2013). Frequentemente, atuam como um metassistema perito, referendando outros sistemas de excelência, as universidades, por exemplo. Estar na capa, local hierarquicamente mais importante de uma publicação, é sinônimo de reconhecimento público (Gadini, 2009) e de distinção social.

Para problematizar o jornalismo feito neste espaço distinto - dedicado aos livros, aos escritores e ao mercado editorial -, utilizamos algumas reflexões de Bourdieu (2008) acerca do capital simbólico no campo cultural e intelectual. O poder de determinado agente ou organização na economia editorial depende da disponibilidade e da articulação dos seguintes capitais: econômico, humano, social, intelectual e simbólico (Thompson, 2013). Nesse contexto, o editor atua, nas palavras de Bourdieu, como um "banqueiro simbólico", empenhando seu prestígio e oferecendo como garantia o capital simbólico que acumulou. Ao selecionar, produzir e divulgar, os editores entram em um ciclo de consagração que dá crédito à sua autoridade. É emblemática, portanto, a definição de Chartier (1999, p.53) acerca desses sujeitos: "empreendedor singular que se vê também como um intelectual e cuja atividade se faz em igualdade com a dos autores".

A seguir, apresentaremos os resultados das análises quantitativas e qualitativas de nosso corpus. Seguindo a orientação de Bardin (2011), reunimos as 160 edições publicadas do Sabático e catalogamos todas as capas a fim de compreender o objeto de forma contextual, buscando o 
estabelecimento de um recorte mais preciso no corpus. Após a definição pelas seis entrevistas com editores de livros, partimos para o desenvolvimento das categorias analíticas que circundam diferentes aspectos destas figuras jornalísticas.

\section{Panorâmica quantitativa das capas: sujeitos, livros e editores}

Na etapa quantitativa de nossa análise, além de medir a presença hegemônica de sujeitos na abertura do suplemento - 74\% -, conforme explicado anteriormente, elencamos outros aspectos, como o sexo e o país de origem de quem esteve em posição de destaque. Os homens são a maioria: 90\%. Percebe-se a ênfase dada à tradição no predomínio de estrangeiros (66\%), especialmente de países hegemônicos tanto do ponto de vista econômico quanto cultural, como Estados Unidos (19\%) e França (7\%), e na porcentagem elevada (54\%) de escritores destacados depois de mortos; ou seja, são índices que apontam para o papel do caderno também na construção da memória e do legado desses autores. Estamos falando, portanto, de figuras já consagradas no meio literário por diferentes instâncias de legitimação, referendadas especialmente pelo meio acadêmico e editorial.

Centramos, então, nosso olhar em outro aspecto que circunda nosso corpus de pesquisa: o livro. A pesquisa de Souza (2012) relaciona a presença dos títulos no Sabático ao valor-notícia de atualidade, neste caso, os lançamentos. Travancas (2001) já havia identificado que a novidadade aparece como uma obrigação na cobertura do mercado editorial feita por suplementos. Para verificar a abrangência do livro como norteador da publicação partimos, mais uma vez, da capa. Catalogamos todas as edições, buscando responder a duas questões: 1) a chamada principal da capa centrase em um único livro? 2) de qual editora é esse volume?

Vieram à tona, então, tensões relativas ao estabelecimento de critérios arbitrários durante a indexação do material. Separamos as edições entre as que destacaram um único título e aquelas que focaram em mais de um. Isso acaba por excluir, portanto, todas as que se dedicaram a dois ou mais livros. A justificativa ancora-se na relevância e na amplitude. Entendemos que, quando o caderno utiliza um único exemplar como gancho ou abordagem central da matéria principal, este confere maior visibilidade e relevo para a pauta em questão. Seguindo esse critério, chegamos a $47 \%$ das edições dedicadas a um único produto. O número é representativo e remonta às conclusões de Souza (2012) e Costa (2012) a respeito do Sabático ser focado no livro, e não em literatura. 


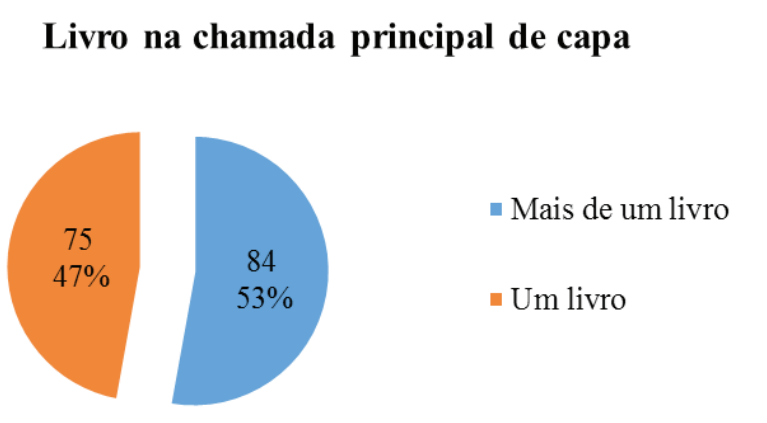

Gráfico 1: a proporção (absoluta e em porcentagem) das edições que se referiram a apenas um livro ou a mais livros. Fonte: dados da pesquisa.

Quantificamos, em seguida, as editoras que publicaram esses livros, $47 \%$ do total, que o Sabático destacou como de maior relevância. Ao todo, 37 editoras estiveram na primeira página com um título, inclusive selos internacionais como Random House, Duke University Press e Library of America. A tabela abaixo mostra as cinco que mais apareceram: Companhia das Letras, Cosac Naify, É Realizações, Objetiva e Record.

\begin{tabular}{|c|c|c|}
\hline Companhia das Letras & $20,55 \%$ & 15 ocorrências \\
\hline Cosac Naify & $9,59 \%$ & 7 ocorrências \\
\hline É Realizações & $6,85 \%$ & 5 ocorrências \\
\hline Objetiva & $6,85 \%$ & 5 ocorrências \\
\hline Record & $5,48 \%$ & 4 ocorrências \\
\hline
\end{tabular}

Tabela 1: as cinco editoras que mais tiveram livros na capa a partir do critério anterior - referência a um único título na chamada principal. Fonte: dados da pesquisa.

Na sequência, com duas ocorrências, estão quatro selos: Alfaguara, Benvirá, José Olympio e Rocco. As demais tiveram apenas um título em destaque na primeira página, incluindo Perspectiva e Martins Fontes, cujos editores foram entrevistados pelo Sabático. É importante ponderar que Record e Objetiva administram diversos selos, que também aparecem em nosso recorte. Pertencem à Record a José Olympio (duas ocorrências), a Civilização Brasileira (uma ocorrência) e a Difel (uma ocorrência). A Alfaguara, que faz parte da Objetiva, também apareceu duas vezes. Ao considerarmos todos os selos, a Record, enquanto grupo editorial, estaria na segunda posição, com nove registros, atrás apenas da Companhia das Letras. 
Das cinco editoras que mais apareceram na capa, portanto, quatro tiveram seus editores entrevistados pelo Sabático. É importante ponderar o espaço concedido à Companhia das Letras, superior às demais, mesmo se considerarmos os selos que pertencem à Record e à Objetiva. Ao mesmo tempo, Luiz Schwarcz, seu fundador, foi o primeiro editor a ser entrevistado e ocupar a capa do caderno. A distinção concedida à Cosac Naify², uma editora criada mais recentemente, em 1997, e que, por muitos anos, dedicou-se aos livros de arte, também merece atenção. Em termos de espaço e visibilidade, ela aparece no Sabático na mesma altura de concorrentes mais tradicionais.

Seguimos, agora, com a leitura qualitativa das entrevistas. A partir do estudo e de anotações sistemáticas sobre o objeto e do seu tensionamento com o referencial teórico, identificamos três índices analíticos regulares: Formação; Rede de Relações e Catálogo. Essas categorias sistemáticas circundam diferentes aspectos dos editores; elas não se sobrepõem, mas têm alto grau de entrelaçamento. Respondem, no coletivo, à construção da figura prestigiosa de um editor de livros a partir do registro jornalístico.

\section{Percurso qualitativo: a formação da competência}

Esta primeira categoria reúne elementos utilizados frequentemente na descrição de caráter pessoal dos editores. Ao destacar determinados aspectos da personalidade, do cotidiano e das competências desses profissionais, o jornalismo constrói uma figura prestigiada em suas páginas. Ao conceder visibilidade a certas características que singularizam esses profissionais, o suplemento cultural acaba por referendar determinada formação de competência ou o que é necessário para ser um editor consagrado.

Isso acontece, em primeiro lugar, porque os editores que compõem nosso corpus detêm um poder institucional relevante, uma vez que comandam editoras representativas no mercado, cujos livros e autores conquistaram também a página mais importante do suplemento. Considerando a importância dada à cultura letrada, têm status e posição privilegiada, o que confere credibilidade ao que falam (Hall, 1999). Em alguma medida, a ênfase dada a esses editores alude ao apontamento de Lipovetsky e Serroy (2011) sobre a criação dos sujeitos célebres, as "estrelas", pelas indústrias culturais. A leitura analítica das entrevistas permite identificar dois índices principais destacados nesta categoria: a herança familiar e habilidade intelectual.

2 Charles Cosac anunciou o fechamento da Cosac Naify em uma entrevista ao jornal O Estado de S. Paulo no dia 30 de novembro de 2015. A editora encerrou as atividades em dezembro de 2015. 
Esses aspectos giram em torno de dois pontos fundamentais na compreensão do que é um editor: o conhecimento e a autoridade. Esse profissional precisa deter um conhecimento, baseado na leitura prévia, que o torna apto a discernir entre obras boas e ruins. Para manter sua autoridade enquanto alguém capaz de selecionar títulos e distinguir autores de referência, os entrevistados enfatizam o desenvolvimento da competência, conquistada pela formação diferenciada ou pelo lastro familiar. Nas seis entrevistas percebe-se a relevância dada a fatores como leitura, distinções acadêmicas e experiência profissional atrelados ao êxito das empresas. É importante dizer que esses editores - e seus selos - são uma instância de legitimação da qualidade artística, em especial para autores iniciantes. A familiaridade com a leitura desponta no corpus, em muitos casos, em memórias que remontam à infância ou à adolescência, como no caso de Roberto Feith, da Objetiva: "O meu sonho profissional era ser jornalista de imprensa escrita; entrei para a TV por mero acaso. Mas sempre fui um leitor voraz, rato de livraria" (FEITH, 2012, p.4, grifo nosso).

A herança familiar é outro eixo que norteia essa categoria. Duas entrevistas dedicam espaço considerável ao tema. São de editores que sucederam seus pais no comando da empresa da família: Sergio Machado, da Record; os irmãos Alexandre e Evandro Martins Fontes. A ênfase ao que foi herdado, ao que remete à memória, remonta a uma das conclusões de Souza (2012) sobre o fato da cobertura do Sabático prezar pela tradição, preferindo aquilo que já está referendado, e pela perenidade, visibilizando produções com valor quase atemporal. A referência às ações paternas também aponta para um prestígio acumulado ao longo de anos e que agora é oferecido como garantia aos filhos, enquanto profissionais, na concepção de banqueiro simbólico (Bourdieu, 2008). Já no texto de capa das entrevistas, é possível perceber alguns elementos que corroboram essa lógica:

Embora atuando separadamente desde 2009, os irmãos Evandro e Alexandre Martins Fontes se mantêm fiéis à orientação do pai, Waldir, que deu início ao negócio: apostar em obras de referência (O ESTADO DE S. PAULO, 2013a, p.4, grifo nosso).

Nosso corpus evidencia que, muitas vezes, o suplemento apresenta um viés romantizado a respeito da sucessão empresarial. A transição do comando é descrita - nos textos de abertura ou em segmentos destacados pela edição jornalística - como algo natural, que não foi permeado por conflitos ou pelo desinteresse dos herdeiros pelo segmento. Nesse momento, são utilizadas expressões como "vocação", "seguir os passos" ou "oferta". A l g u m a s das respostas dos editores apontam, no entanto, para uma imposição dos fundadores em relação à sucessão. Ao ser questionado se escolheu livremente 
trabalhar na editora, Sergio Machado, da Record, respondeu com ironia - uma proposta que não poderia recusar - citando um trecho do filme O Poderoso Chefão: "I had an offer I couldn't refuse. My father made me an offer I couldn't refuse" (MACHADO, 2012, p.4). No total, a entrevista de Sergio Machado teve 38 perguntas publicadas e, em onze delas, o assunto principal é a história da editora, referente à ação de seu fundador e a sua relação como sucessor. No caso dos irmãos Martins Fontes, sete das 29 perguntas dizem respeito à questão histórica. Essa proporção quantitativa evidencia o modo como o conjunto das matérias destacou amplamente uma temática em detrimento de outras. Nas duas entrevistas, foram utilizadas fotografias dos fundadores das empresas, outro artifício do jornal em reiterar aquilo que sobrevive ao passar do tempo, que é tradicional. Assim, ser herdeiro ou afiançar o legado deixado pela família é uma característica enfatizada na trajetória desses editores como algo positivo e relevante.

A questão do legado também aparece no caso de Luiz Schwarcz, que fundou a Companhia das Letras, e de Jacó Guinsburg, criador da Perspectiva. O texto de abertura da entrevista de Schwarcz, na página central, acentua a "origem judaica". O editor também faz referência à família, ao falar de suas obras de ficção. No caso de Guinsburg, que inclusive publica literatura ídiche, a proximidade com a cultura judaica é enfatizada em momentos distintos ao longo da narrativa assinada pelo repórter Antonio Gonçalves Filho:

Vindo da Bessarábia com 3 anos, ele frequentava na adolescência o clube judeu Cultura e Progresso no Bom Retiro, depois transformado na Casa do Povo ${ }^{3}$. 'Devia ter uns 12 ou 13 anos quando assisti a uma peça antirreligiosa em plena época das festas judaicas', conta, rindo (GONÇALVES FILHO, 2012, p.5, grifo nosso).

Essa primeira categoria permite, portanto, algumas inferências sobre o modo como o suplemento desenvolve a figura desses editores. 0 primeiro aspecto é a tradição. Aquilo que remete ao legado familiar ganha espaço e destaque jornalístico, sendo apresentado como fator essencial para o desenvolvimento da empresa. Algumas entrevistas, especialmente a de Sergio Machado e a dos irmãos Martins Fontes, reforçam isso. O segundo aspecto refere-se à questão intelectual. Apesar das diferentes abordagens, o conhecimento surge como um pilar fundamental para esses profissionais - seja de arte, como Charles Cosac, ou de jornalismo, no caso de Roberto Feith. O último ponto enfatizado como determinante na personalidade desses editores é a habilidade de leitura formada desde a infância. Nesse quesito,

3 Espaço criado em 1953 no bairro Bom Retiro, em São Paulo, em memória dos que morreram nos campos de concentração nazistas. Segundo o material institucional da Casa do Povo, seus criadores vieram da Europa Oriental, falavam ídiche e defendiam uma cultura laica. Material disponível em: casadopovo.org.br Acesso em: Janeiro de 2015. 
é possível distinguir posicionamentos distintos daqueles que são herdeiros e dos editores que criaram suas empresas. Os primeiros ancoram-se na tradição, enquanto os demais reforçam o viés da criação relacionado às suas competências.

Essas características, selecionadas pelo Sabático, apresentam-se como índices de prestígio, uma vez que são fundamentais para que esses profissionais se mantenham em posição de autoridade, baseada no conhecimento e na tradição, para avaliar a qualidade artística das obras. Ao conferir significado a esses aspectos, o jornalismo, conforme afirma Hall (1999), projeta um mapa que permite identificar valores consensuais sobre o que é ser um editor prestigiado. O recorte analisado indica que, para ocupar tal lugar, é preciso ser leitor qualificado e, se possível, estar ancorado na tradição.

\section{Rede de Relações}

Os sujeitos com quem o editor de livros mantém relação estreita constituem outro índice importante. Assim como os editores podem empenhar sua reputação a favor de uma obra ou de um escritor iniciante, esses profissionais também se apoiam em outros sujeitos prestigiados. Bourdieu (2008) apontou, ainda que brevemente, a capacidade do jornalismo de atuar na transferência de capital simbólico. Seguindo esse raciocínio, consideramos que nos referimos a um espaço distinto, restrito e de temporalidade alargada, o suplemento, capaz de atuar nessa transferência entre agentes e produtos.

A Rede de Relações dos editores entrevistados abrange diferentes aspectos: catálogo, desenvolvimento profissional, questões econômicas e sistemas de excelência são alguns deles. Os exemplos abaixo evidenciam como as conexões dos editores podem afetar a formação do catálogo de suas empresas. Destaca-se, aqui, a importância das relações com agentes e editoras internacionais, que parecem ter papel decisivo neste contexto:

Não quero tirar o mérito do outro editor, mas eu já era bem amigo da Liz Calder (editora inglesa que descobriu J.K. Rowling) na época. Ou seja, tive a informação do sucesso de Harry Potter muito antes de virar fenômeno (SCHWARCZ, 2011, p.4, grifo nosso).

Eu tinha muito contato com a Yale University Press, e ela abriu portas para mim. Licenciei vários livros da Yale quando John Nicoll estava lá. Como minha editora era pequenininha, era difícil quebrar nichos - e eu precisava de muitas cartas de referência e de crédito (COSAC, 2013, p.4, grifo nosso).

Há cinco anos descobri por meio de um amigo a obra da 
pintora Eleonore Koch, cujo livro sai agora em maio. Quando vi pela primeira vez uma tela sua, me deu um frio na espinha. O livro de Lore Koch estava com outra editora e não entraria jamais em concorrência para ter o direito de publicá-lo. Felizmente, o advogado da artista me procurou oferecendo o título (COSAC, 2013, p.5, grifo nosso).

Charles Cosac associa o tamanho reduzido de sua editora, no período em que foi criada, com certa dificuldade na aquisição de títulos. Ele menciona a necessidade de "cartas de referência e de crédito" para publicar. No trecho seguinte, conta que os direitos sobre a obra da pintora Eleonore Koch foram oferecidos a ele pelo advogado da artista. Há uma grande diferença entre as duas situações, separadas pelo tempo e pela sedimentação da Cosac Naify no mercado. Podemos dizer que os dois depoimentos sobre períodos distintos evidenciam o quanto a reputação e o reconhecimento público são capazes de atuar no contexto de relações editoriais.

A entrevista de Jacó Guinsburg também denota a força da rede de sociabilidade, dessa vez no desenvolvimento profissional do editor em questão. A narrativa jornalística revela que a carreira de Guinsburg, como professor de artes dramáticas na Universidade de São Paulo, perpassa a história do Suplemento Literário de O Estado de S. Paulo. A sequência de fatos narrados faz das relações entre intelectuais um eixo fundamental na carreira desse editor. Quando fundou a sua editora, a ajuda de parceiros foi decisiva: "Ela começou como uma sociedade fechada com muitos sócios, entre eles Celso Lafer $^{4}$ e José Mindlin ${ }^{5}$, que nos ajudou em muitos outros momentos de crise, como nos anos 1970, quando quase fomos à barrocada" (GONÇALVES FILHO, 2012, p.5). A partir da trajetória de Lafer e Mindlin - o primeiro foi ministro em dois governos, enquanto o segundo era um empresário importante do setor automotivo - podemos perceber que essa proximidade denota, também, a importância do poder econômico e simbólico na trajetória de Jacó, indo além do campo da cultura. E essa movimentação é reforçada pelo material jornalístico, que visibiliza tais aspectos, destacando-os como relevantes na compreensão do que é um editor consagrado.

As relações que circundam o capital econômico das editoras são fundamentais para a compreensão dos indivíduos que as comandam. Isso se deve à importância desse aspecto para a manutenção das empresas e também a algumas particularidades do mercado brasileiro. No caso dos

\footnotetext{
4 Jurista e professor da USP, Celso Lafer foi ministro do Desenvolvimento, Indústria e Comércio em 1999. É membro da Academia Brasileira de Letras e foi duas vezes ministro das Relações Exteriores, em 1992 e 2001 . Atualmente, é presidente do Conselho Superior da Fundação de Amparo à Pesquisa do Estado de São Paulo (Fapesp).

5 Empresário do setor de peças para automóveis, advogado e escritor. De origem judaica, José Mindlin também foi membro da Academia Brasileira de Letras. Colecionador de livros raros, Mindlin reuniu mais de 30 mil títulos. A coleção do bibliófilo foi doada à Universidade de São Paulo e está em uma biblioteca que leva seu nome e de sua esposa, Guita.
} 
programas de compras de títulos pelo governo, responsáveis por boa parte dos exemplares vendidos no país, percebe-se certa ambiguidade no modo de dizer dos entrevistados, que ao mesmo tempo se aproximam e se distanciam dessas ações.

Os programas de apoio são sempre interessantes, complementares. Agora não vejo que isso vá mudar a história dos autores já consagrados. Mas o governo tem um papel importante, sobretudo o de São Paulo, que tem um programa ambicioso: de dar o livro (MACHADO, 2012, p.5, grifo nosso).

Apesar dos dados - o governo federal, conforme Lindoso (2014), adquiriu 200,30 milhões de exemplares em 2010, quase a metade da produção nacional -, o editor não assegura um papel central para essa ação. Estamos, certamente, em um universo de respostas que passam pelo crivo da produção do Sabático e, nesse universo, os editores que vêm a público tendem a tangenciar a questão, afirmando que "incomoda menos" ou é "complementar". Denotam, em alguma medida, que preferem manter uma posição mais independente, sem jamais demonstrar resignação ou dependência em relação à venda para o governo.

Quando a conexão se dá com marcas hegemônicas em seus mercados, como Amazon, Apple ou Google, o posicionamento é outro. Primeiro, porque os editores querem dizer que estão em negociação com essas empresas, então relatam proximidade e acabam respondendo a mais de uma pergunta sobre o tema. Algo parecido acontece quando o assunto é a tecnologia, novos formatos, os livros digitais em si. Abordar essa questão é um modo de se mostrar atualizado, ciente das mudanças tecnológicas. Mais uma forma, então, de manter o capital simbólico adquirido.

Nós, brasileiros, estamos numa posição muito melhor que a Random House. Podemos dizer para a Amazon o que eles não podem (MACHADO, 2012b, p.5, grifo nosso).

O e-book está aí e veio para ficar. Não tem um editor no mundo que possa se dar ao luxo de não dar atenção para esse assunto (FONTES, 2012a, p.5, grifo nosso).

Outro ponto fundamental são os sujeitos notórios. Essa associação acontece em todas as entrevistas, de maneira mais ou menos evidente. Em algumas delas, como na de Luiz Schwarcz, o editor aparece em fotos com figuras célebres: a escritora Lygia Fagundes Telles e o português José Saramago, vencedor do prêmio Nobel de Literatura. A presença dos dois, considerados cânones, colabora para a composição jornalística do editor enquanto um profissional habilitado para identificar autores de qualidade. Ao mesmo tempo, são nomes conhecidos do público. Ao associar o editor à 
imagem deles, o Sabático aproxima o entrevistado de seus leitores. Utiliza-se, assim, da personalização enquanto um recurso capaz de gerar identificação com quem acessa esse conteúdo.

É interessante a relevância dada, nas respostas de Schwarcz, à ligação com uma das mais importantes orquestras sinfônicas do país, a Osesp ${ }^{6}$, e, por consequência, com a cultura erudita a partir da música clássica, além da referência à Festa Literária Internacional de Paraty (Flip) ${ }^{7}$. Enquanto ocupa dezoito linhas para falar da Osesp e Flip, o editor afirma, em uma única frase, não se aproximar das entidades que representam os editores de livros, sem ao menos citá-las. Percebe-se, a partir dos conteúdos editados, um distanciamento dessas instituições.

A entrevista de Roberto Feith permite análise semelhante. Também em uma referência ao catálogo e à proximidade com o mercado editorial internacional, o caderno publicou uma foto do editor com John Freeman, da revista britânica Granta $^{8}$. A Objetiva lançou uma versão brasileira da publicação com textos de jovens autores, e a foto foi feita no lançamento da edição. Nesse caso, tanto a presença do editor inglês quanto a marca da revista - uma referência na área editorial em todo o mundo - atuam na construção da figura de Feith como profissional qualificado e renomado.

A partir disso, é interessante perceber o modo como o jornalismo confere visibilidade a determinados sistemas de excelência, atuando como metassistema perito (Miguel, 1999). A relevância dada à revista Granta, à Osesp e ao escritor Saramago são bons exemplos. Os três angariaram, ao longo do tempo, mérito e prestígio em suas áreas, o que os aproxima da excelência técnica. Ao conceder visibilidade a esses sistemas - e não a outros -, o suplemento aciona a crença do público na legitimidade que adquiriram. Ou seja, afiançar sua relevância implica em dizer que os editores a eles relacionados também são relevantes.

Podemos afirmar, a partir desta categoria, que as personalidades entrevistadas pelo Sabático buscam apoiar sua imagem em sujeitos e instituições que detêm prestígio, o que é visibilizado pelo suplemento. Do ponto de vista econômico, estamos falando de empresas ou empresários de grande porte, com relevância nacional e internacional. O caráter grandioso

6 A Orquestra Sinfônica do Estado de São Paulo (Osesp) iniciou suas atividades em 1953, e a lei estadual que regulamenta seu funcionamento é do ano seguinte, 1954. Entre os membros instituidores da Fundação Osesp estão o expresidente da República Fernando Henrique Cardoso e o editor Luiz Schwarcz. Informações disponíveis em: www.osesp. art.br/paginadinamica.aspx?pagina=linhadotempo Acesso em: janeiro de 2015.

7 A primeira edição da Festa Literária Internacional de Paraty (Flip) ocorreu em 2003, com a presença de autores renomados como Eric Hobsbawm. O evento acontece em Paraty (RJ), anualmente, e foi idealizado pela editora inglesa Liz Calder. Informações disponíveis em: www.flip.org.br e www.paraty.tur.br/flip.php Acesso em: janeiro de 2015.

8 Revista criada em 1889 por alunos da Universidade de Cambridge, na Inglaterra, a "The Granta" publicou os primeiros textos de autores importantes como Ted Hughes e Sylvia Plath. É considerada uma das publicações literárias de maior prestígio. A Editora Objetiva publica, pelo selo Alfaguara, várias edições da revista no Brasil. 
de alguns (Google, Amazon, Apple e Penguin, por exemplo) sugere a ideia de igualdade em relação ao tamanho desses editores, no sentido de que só quem é grande é capaz de aproximar-se de gigantes. Essa relação faz com que as empresas comandadas pelos entrevistados se alimentem do prestígio obtido pelos editores e cresçam com ele.

As referências encontradas no texto e nas fotos remetem a sistemas de excelência, sejam eles autores renomados, uma revista ou um evento. Mesmo quando a associação não é com o campo editorial, caso da Osesp, identifica-se algo em comum: a cultura legitimada, erudita, em alguns casos. Evidenciam-se ainda valores caros ao Sabático, como a cultura letrada, o livro e a tradição. Não é possível identificar, por exemplo, uma associação desses editores a elementos atrelados à cultura de outros matizes, como o hip hop, ou a escritores do meio digital, como blogueiros. Unem-se ao que é referência, ou seja, àquilo que já passou por diferentes instâncias de legitimação. E essa construção jornalística se dá em um espaço de distinção - o suplemento, capaz de apontar o que é relevante entre as produções artísticas, atuando como um intermediário no sistema cultural (Sirena, 2014).

\section{Catálogo}

A função de um editor de livros implica, obrigatoriamente, na seleção do que será publicado. Os editores entrevistados pelo Sabático também carregam características de um publisher, que assume outras atividades, como a busca de autores para escreverem determinado título, o gerenciamento e a avaliação de riscos para a empresa. No Brasil, é comum acumular a ação de publisher, mais comercial, com a seleção de originais (Oliveira, 2013). O viés tradicional da profissão remonta à ideia de um leitor qualificado, capaz de garimpar bons textos.

A originalidade de uma obra é um conceito importante na tentativa de definir a qualidade artística. São as instâncias de legitimação que costumam atuar fortemente nesse processo. Publicar títulos assinados por autores reconhecidos auxilia na formação do capital simbólico de uma editora. Por esse motivo, como explica Thompson (2013), as editoras não abraçam de boa vontade a ideia de publicar livros de segunda categoria.

Diferentes índices de prestígio fazem referência aos títulos que esses editores - e por consequência, as empresas que comandam - decidem publicar. Podemos destacar duas grandes temáticas: os autores e os tipos de livros. O primeiro tema relaciona-se com a posição central do criador no processo de criação de valor. A capacidade de garimpar novos autores ou a compra dos direitos de títulos inéditos no Brasil são iniciativas centrais para 
as editoras:

Quando voltei ao Brasil conheci a obra do arquiteto Paulo Mendes da Rocha. Três editoras tentaram tirar o livro de mim e eu falei: vocês estavam aqui há milhões de anos e não viram. Foi meu olhar estrangeiro que me permitiu ver aquilo que quem estava aqui não via (COSAC, 2013, p.5, grifo nosso).

A fala editada dos entrevistados - e a narrativa jornalística, no caso de Jacó Guinsburg - evidencia a descoberta, o pioneirismo e também as dificuldades inerentes ao processo. Outro movimento interessante de distinção diz respeito aos escritores. Alguns deles acabam tendo seu nome usado como marca, uma grife de valor que legitima tanto os editores como os selos. Conforme Bourdieu (2008), o valor distintivo de um produto depende da estrutura do campo em que está inserido. No mercado dos livros, diferentes fatores atuam nesse processo. Quando falamos de autores referenciais, o nome costuma ser o suficiente para a evidência do prestígio imbuído. Percebemos isso no seguinte trecho:

Mas a importância de Milton Hatoum, Bernardo Carvalho, Chico Buarque, Daniel Galera, Lourenço Mutarelli e outros que estamos publicando é equivalente à de Rubem (Fonseca). Por exemplo, um livro do Milton Hatoum, como Dois Irmãos, já vendeu 70 mil exemplares (SCHWARCZ, 2011, p.5, grifo nosso).

Apesar de o editor da Companhia das Letras complementar a frase com as vendas de um título de Milton Hatoum, não há outros esclarecimentos sobre os autores mencionados. Do ponto de vista jornalístico, o discurso evidencia a interlocução com um leitor que detém conhecimento sobre literatura. $\mathrm{Na}$ mesma lógica, Roberto Feith, da Objetiva, detalha o pensamento por trás da coleção Plenos Pecados: "Uma das razões de montar esse projeto era atrair autores de renome para uma editora ainda sem grande visibilidade ou trajetória consolidada" (FEITH, 2012, p.5, grifo nosso). Criada por ele, a coleção foi definida como "uma série com autores de prestígio escrevendo a respeito de temas mais palatáveis" (O ESTADO DE S. PAULO, 2012c, p.4-5). Entre os autores que assinam livros na coleção estão João Ubaldo Ribeiro, Zuenir Ventura, Luis Fernando Verissimo e João Gilberto Noll. A afirmação de Feith esclarece o quanto os autores publicados - e sua notabilidade - podem ser fundamentais para uma editora, em especial nas recém-criadas.

Para compreender de que forma o prestígio cerca o catálogo das editoras, é preciso chegar aos livros de ciclo longo e de ciclo curto. O conceito foi desenvolvido por Bourdieu (2008) em referência ao mercado editorial francês. O objetivo era diferenciar editoras que produziam títulos de venda 
imediata - os best-sellers - daqueles que necessitam de tempo e prestígio para garantirem as vendas. Thompson (2013) recorre à definição quando analisa o fato de a venda logo após o lançamento ser sinônimo de sucesso editorial atualmente. Os irmãos Evandro e Alexandre Martins Fontes abordam o assunto, defendendo os livros de ciclo longo, mesmo posicionamento de seu pai, fundador da editora:

Alexandre falou bem: é difícil dizer não para um livro que vende 300 mil exemplares num curto espaço de tempo. Mas minha preocupação é com a formação de um catálogo e com a busca de long-sellers (FONTES, 2012b, p.4, grifo nosso).

Thompson (2013) e Benhamou (2007) afirmam que parte das editoras busca equilibrar títulos dos dois tipos para manter o capital simbólico e o econômico. Os dados obtidos nas entrevistas indicam que a estratégia realmente é utilizada, mas existe certo receio de admitir esse recurso. As críticas aos best-sellers e a defesa dos livros de tempo longo são recorrentes na fala editada e publicada no Sabático. Da mesma forma, o número de exemplares vendidos, geralmente maior em livros de tempo curto, é comemorado.

O ponto de vista econômico parece predominar na seleção jornalística, uma vez que parte significativa dos destaques - fotos e textos - diz respeito a títulos que venderam uma quantidade considerável. O suplemento reverencia, então, tudo que é notável e superlativo. As entrevistas que têm barra inferior com imagens (todas as publicações, exceto a dedicada a Jacó Guinsburg) trazem informações referentes aos sucessos de vendas. Encontramos aí um viés laudatório, que remete às informações institucionais publicadas nos sites das empresas.

Ao ser questionado se publicaria livros de Paulo Coelho, um campeão de vendas, Luiz Schwarcz (2011, p.4, grifo nosso) responde do seguinte modo: "Uma pergunta complicada, essa... Eu acho que, se a Companhia tivesse um outro selo, já teria publicado Paulo Coelho. Mas no selo da Companhia acho que não faríamos um bom trabalho para Paulo Coelho". Apesar de não explicar ou aprofundar a questão, a resposta indica que o autor não se encaixa no perfil da editora nem do seu público-alvo. Ao mesmo tempo, é possível perceber um grau de ambiguidade ou de ironia em sua fala. Isso porque, em outros momentos da entrevista, Schwarcz faz referência positiva a outras obras que venderam milhares de exemplares, como Harry Potter. Em um movimento semelhante, Charles Cosac critica o best-seller Capitão Cueca, um de seus recordistas de venda, indicado para publicação por sua irmã. Em contrapartida, no parágrafo seguinte, afirma que brigou para manter no 
catálogo a obra do arquiteto Paulo Mendes da Rocha9, vencedor do Prêmio Pritzker, um dos mais destacados da arquitetura mundial. Aproxima-se, desse modo, de um sistema de excelência, como falamos na categoria anterior.

A análise de aspectos que circundam a questão do catálogo evidencia um ponto importante sobre a personalização dos editores entrevistados. Os livros são aproximados da figura deles de uma forma semelhante à dos escritores, responsáveis por sua criação. O prestígio desses editores - e de suas empresas - depende dos livros que escolhem publicar, uma vez que estamos falando de sujeitos autorizados a selecionar o que é bom e merece ser publicado. Por isso, também, todos fazem referência a autores legitimados a partir do nome, da grife que construíram. Ao mesmo tempo, os editores demonstram, a partir das matérias, algum constrangimento em se associarem a livros que vendem milhares de exemplares, mas de conteúdo questionável. A edição do suplemento diz que os cânones são importantes, porém evidencia os recordistas de venda. Esse movimento quase paradoxal aponta para o caráter central do superlativo para o jornalismo cultural, seja em relação aos cânones ou às vendas.

Do ponto de vista da construção jornalística da figura dos editores, podemos perceber que os autores legitimados e os livros de ciclo longo são importantes índices de consagração. Há, ao mesmo tempo, relativo afastamento dos best-sellers. Os editores apoiam seu prestígio no capital simbólico do catálogo que estruturam. E isso se dá porque sua função pressupõe autoridade e leitura qualificada para escolher o melhor para ser transformado em livro.

\section{Considerações finais}

Concluímos, a partir do recorte analisado, que a figura dos editores de livros foi construída pelo suplemento, reverenciando elementos de distinção distribuídos nos anos de formação, nas relações cultivadas ou no catálogo garimpado. Nas entrevistas jornalísticas - ou seja, determinadas visadas sobre os sujeitos -, quando os depoentes entendem que seu prestígio pode ser abalado, tergiversam. A narrativa ampara esse movimento, apresentando ao público uma personalidade ancorada naquilo que Ihe interessa mostrar, transgredindo tal lógica em poucos momentos. Em geral, nota-se ausência de

9 Arquiteto e Urbanista formado pela Universidade Presbiteriana Mackenzie, de São Paulo, nasceu em Vitória, Espírito Santo, em 1928. Foi professor da USP, cassado durante a ditadura militar. Recebeu o Prêmio Pritzker, considerado o mais importante da arquitetura mundial, em 2006. Informações disponíveis em: paulomendesdarocha.wordpress.com/perfil. Acesso em: janeiro de 2015. 
conflito nas matérias editadas.

Cabe reforçar o viés positivo das trajetórias retratadas pelo Sabático. Nos perfis, os editores aparecem como sujeitos que conquistaram o sucesso e o capital simbólico necessário à atividade, ultrapassando poucos desafios - ou praticamente nenhum. São retratados no jornal sorrindo nas fotos ou com um semblante sério que denota competência, o que acentua o viés romantizado. Os títulos escolhidos pela edição jornalística reforçam o caráter distintivo. Mesmo em questões emergentes e complexas, como os livros digitais, não há ênfase ao embate, mas à solução. Os editores são retratados como sujeitos capazes de resolver questões de modo construtivo.

Ao afiançar a fala dos editores, o suplemento cultural cola o sucesso das editoras à capacidade de quem as comanda. São indivíduos prestigiados, tão capazes e bem relacionados, que têm atuação determinante para as empresas que lideram. O sucesso das editoras é atrelado aos elementos de distinção que cada editor de livros reúne. O consenso jornalístico proposto sobre os editores de prestígio abrange sujeitos que mantêm a herança familiar, têm formação erudita e desenvolvem competências, circulam no ambiente dos negócios, relacionam-se com pessoas e marcas renomadas e, por isso, são capazes de escolher os melhores textos, aqueles que são dignos de serem transformados em um objeto de valor referencial, o livro.

\section{Referências}

BARDIN, Laurence. Análise de conteúdo. São Paulo: Edições 70, 2011.

BENETTI, Marcia. O jornalismo como gênero discursivo. Galáxia. n.15. São Paulo: PUC-SP, 2008.

BENHAMOU, Françoise. A economia da Cultura. Cotia, SP: Ateliê Editorial, 2007.

BERGER, Christa. Campos em confronto: a terra e o texto. 2a ed. Porto Alegre: Editora da UFRGS, 2003.

BOURDIEU, Pierre. Coisas ditas. São Paulo: Brasiliense, 2004.

- A produção da crença: contribuição para uma economia dos bens simbólicos. $3^{a}$ ed. Porto Alegre: Zouk, 2008.

O Poder Simbólico. 14ª ed. Rio de Janeiro: Bertrand Brasil, 2010.

Zouk, 2011.

A distinção: crítica social do julgamento. $2^{a}$ ed. Porto Alegre:

BRAGANÇA, Aníbal. Uma introdução à história editorial brasileira. In: Cultura (Lisboa). II série, v. XIV, 2002, p. 57-83. 
Sobre o editor. Notas para a sua história. In: Em Questão, v.11, n.2, jul./dez, 2005, p.219-237.

CHARTIER, Roger. A aventura do livro: do leitor ao navegador. São Paulo: Editora Unesp/ Imprensa Oficial do Estado, 1999.

COSTA, Juliana Meres. Sabático: um novo tempo para a leitura? (A retomada do Suplemento Literário no Estado de S. Paulo). 2012. Dissertação (Mestrado em Divulgação Científica e Cultural) - Instituto de Estudos da Linguagem e Laboratório de Estudos Avançados em Jornalismo, Universidade Estadual de Campinas. Campinas, 2012.

FEITH, Roberto. "A pirataria online pode minar a produção do conhecimento". Entrevistadores: Rinaldo Gama et al. O Estado de S. Paulo: São Paulo, 25 agosto 2012. Sabático, p. 4-5.

FONTES, Alexandre Martins. Um legado a duas vozes. Entrevistadores: Rinaldo Gama, Antonio Gonçalves Filho e Maria Fernanda Rodrigues. O Estado de S. Paulo: São Paulo, 2 fevereiro 2013. Sabático, p. 4-5.

FONTES, Evandro Martins. Um legado a duas vozes. Entrevistadores: Rinaldo Gama, Antonio Gonçalves Filho e Maria Fernanda Rodrigues. O Estado de S. Paulo: São Paulo, 2 fevereiro 2013. Sabático, p. 4-5.

GADINI, Sérgio Luiz. Interesses cruzados: a produção da cultura no jornalismo brasileiro. São Paulo: Paulus, 2009.

GOLIN, Cida ; CARDOSO, Everton. Jornalismo e a representação do sistema de produção cultural: mediação e visibilidade. In: BOLAÑO, César; GOLIN, Cida; BRITOS, Valério (Org.). Economia da arte e da cultura. São Paulo: Itaú Cultural; São Leopoldo: Cepos/Unisinos; Porto Alegre: PPGCOM/UFRGS; São Cristóvão: Obscom/UFS, 2010. p.184 a 203.

et al. O arquivo no espaço do efêmero: a consolidação do formato suplemento cultural na imprensa do RS em 1967. Dossiê Mídia, Intelectuais e Política - www.pos.eco.ufrj.br - ISSN 2175-8689 - v.16, n.2, p.107-124, mai./ago. 2013.

GONÇALVES FILHO, Antonio. Editor dos grandes mestres [entrevista com Jacó Guinsburg]. O Estado de S. Paulo, São Paulo, fev. 2012. Sabático. p.4-5.

HALL, Stuart et al. A produção social das notícias: o mugging nos media. In: TRAQUINA, Nelson (Org). $2^{a}$ ed. Jornalismo: questões, teorias e estórias. Lisboa: Vega, 1999, p. 224-262.

LIPOVETSKY, Gilles; SERROY, Jean. A cultura-mundo: resposta a uma sociedade desorientada. São Paulo: Companhia das Letras, 2011.

LINDOSO, Felipe. Panorama do setor editorial brasileiro. In: Revista Observatório Itaú Cultural. São Paulo: Itaú Cultural, 2007. n. 17 (ago./ dez.2014).

LORENZOTTI, Elizabeth. Suplemento literário: que falta ele faz!: 19561974 do artístico ao jornalístico: vida e morte de um caderno cultural. São 
Paulo: Imprensa Oficial do Estado de São Paulo, 2007.

MACHADO, Sergio. "Sou comprador e vendedor: é tudo uma questão de preço". Entrevistadores: Rinaldo Gama, Maria Fernanda Rodrigues e Ubiratan Brasil. 0 Estado de S. Paulo: São Paulo, 26 maio 2012. Sabático, p. 4-5.

MIGUEL, Luis Felipe. O jornalismo como sistema perito. In: Tempo social: Revista de Sociologia, v.11, n.1, São Paulo: USP, 1999.

SIRENA, Mariana. O circuito artístico de Porto Alegre na década de 1950 a partir do jornalismo: análise da coluna Notas de Arte, de Aldo Obino, no Correio do Povo. 2014. Dissertação (Mestrado em Comunicação e Informação) - Programa de Pós-Graduação em Comunicação e Informação, Universidade Federal do Rio Grande do Sul. Porto Alegre, 2014.

SCHWARCZ, Luiz. Rumo a uma nova estação editorial. Entrevistadores: Rinaldo Gama et al. O Estado de S. Paulo: São Paulo, 30 julho 2011. Sabático, p. 4-5.

SOUZA, Karla Beraldo de. A tradição legitimada: um estudo sobre o suplemento literário Sabático, do jornal O Estado de S. Paulo. 2012. Dissertação (Mestrado em Comunicação) - Programa de Pós-Graduação em Comunicação, Universidade Estadual Paulista "Júlio de Mesquita Filho". Bauru, 2012.

THOMPSON, John. Mercadores de cultura: o mercado editorial no século XXI. São Paulo: Editora Unesp, 2013.

TOLILA, Paul. Cultura e economia: problemas, hipóteses, pistas. São Paulo: Iluminuras: Itaú Cultural, 2007.

TRAQUINA, Nelson. As notícias. In: TRAQUINA, Nelson (org.). Jornalismo: questões, teorias e "estórias". Lisboa: Vega, 1999.

TRAVANCAS, Isabel. O livro no jornal: os suplementos literários dos jornais franceses e brasileiros nos anos 90. Cotia: Ateliê Editorial, 2001.

\section{Materiais Jornalísticos utilizados:}

O ESTADO DE S. PAULO. Sabático. Com a palavra, o editor: Rumo a uma nova estação editorial. O Estado de S. Paulo: São Paulo. 30 de julho de 2011. p.1, 4-5.

O ESTADO DE S. PAULO. Sabático. No palco dos livros: Editor dos grandes mestres. 0 Estado de S. Paulo: São Paulo. 18 de fevereiro de 2012a. p.1, 4-5.

O ESTADO DE S. PAULO. Sabático. Profissão: editor: "Sou comprador e vendedor: é tudo uma questão de preço". O Estado de S. Paulo: São Paulo. 26 de maio de 2012b. p.1, 4-5.

O ESTADO DE S. PAULO. Sabático. Horizonte editorial: "A pirataria online 
pode minar a produção do conhecimento". O Estado de S. Paulo: São Paulo. 25 de agosto de 2012c. p.1, 4-5.

O ESTADO DE S. PAULO. Sabático. Vocação familiar: Um legado a duas vozes. O Estado de S. Paulo: São Paulo. 2 de fevereiro de 2013a. p.1, 4-5.

O ESTADO DE S. PAULO. Sabático. A arte de editar arte: Um editor e a arte de andar na contramão do mercado. O Estado de S. Paulo: São Paulo. 20 de abril de 2013b. p.1, 4-5. 